\title{
The Impact of Local and Global Conjunctions on ESL Reading Comprehension: A Systemic Perspective
}

\author{
Nader Assadi Aidinlou \\ Islamic Azad University, Ahar Branch, Iran \\ Email: naderasadi@yahoo.com \\ Ambigapathy A/L Pandian \\ School of Languages, Literacies and Translation, USM 1800, Malaysia \\ Email: ambiga@usm.my
}

\begin{abstract}
This paper investigated the impact of conjunctions on the reading comprehension of ESL learners. To this end, three different versions; original, local-conjunctions-free and global-conjunctions-free, of an IELTS reading test where the logico-semantic relationships had been manipulated were administered to 45 upper-intermediate subjects assigned to three equal groups. The results indicated that the performance of the groups on reading comprehension was significant: the group receiving the unmodified test outperformed the other two; and the group taking the local-conjunctions-free test performed better than the other. It was concluded that conjunctions employed to link and texture the information at the local and global levels across the text affected the reading comprehension of ESL learners, and more importantly that the global conjunctions influenced reading comprehension more than the local conjunctions.
\end{abstract}

Index Terms - local and global conjunctions, logico-semantic relationships, reading comprehension

\section{INTRODUCTION}

Reading is complex and the development of fluent reading abilities by second language students is a challenging undertaking. Grabe and Stoller (2002) assert that reading comprehension is remarkably complex, involving many lower- and higher-level processing skills that are coordinated in very efficient combinations. This is the very point at which ESL and EFL learners confront tremendous problems in the act of reading, because they do not adopt an interactive orientation towards the entire written text (Carrell, 1988; Grabe, 1988; Eskey, 1988). For example, foreign language learners can read in small text units such as clauses and sentences; nonetheless, they need more experience to be able to form the correct global meaning of the written text. This necessitates, for reading comprehension, the ability to work out the relationships at the local and global levels of the text (Lotfipour, 2006). Conjunctions are one of the linguistic resources that provide the ground for the understanding of the local and global relationships between messages, events and sequences of activities throughout the text.

Based on the systemic model (Halliday \& Hasan, 1976; Halliday \& Matthiessen, 2004; Martin, 1992), the present study uses conjunctions to refer to all the linking words that hold logico-semantic relationships at the micro- and macrolevels of the text. Accordingly, any conjunction carries two kinds of meaning: experiential meaning and logical meaning. From the logical point of view, they appear in either a local context or a global context; and from the experiential viewpoint, they establish three semantic relationships; that is, elaboration, extension and enhancement, between clauses (complexes).

Local conjunctions are concerned with the relationships that are restricted to the scope of the clause and clause complex. These conjunctions are encoded by prepositional phrases within the clause and by coordinators or subordinators within the clause complex. The former is beyond the scope of this paper, because prepositions are the marked realizations of the conjunctions (Halliday \& Matthiessen, 2004; Martin, 1992), but the relationships within clause complexes are set by two different types of conjunctions: paratactic and hypotactic.

Paratactic conjunctions give rise to the interdependency relationships between two independent clauses of equal status. For example:

(1) A few days have gone by since Hari Raya, but I have not sent a Selamat Hari Raya card to some of my Muslim colleagues yet.

In the clause complex above, the two equal clauses are linked by means of the conjunction but. It is noteworthy that events in the clauses joined paratactically are arranged sequentially, so any change in the order will affect the chronological occurrence of the events. 
Hypotactic conjunctions, on the contrary, give rise to the dependency relationships between two clauses of unequal status. That is to say, a conjunction-bearing clause called dependent clause $(\beta)$ rests on another clause called dominant clause $(\alpha)$. Unlike the paratactic sequencing, the hypotactically-related clauses can appear as either ' $\alpha$ plus $\beta$ ' or ' $\beta$ plus $\alpha^{\prime}$. In English, the former is unmarked (as in Example 2), and the latter is used only when there is an acceptable reason (as in Example 3).

(2) Alice went out for walk because she felt very lonely at home. ( $\alpha$ plus $\beta$ )

(3) Before she leaves the house, she double-checks everything. ( $\beta$ plus $\alpha$ )

Global conjunctions go beyond the scope of the structure of the clause to include the relationships between clause complexes and paragraphs across the text. They typically appear at the beginning of a sentence or a paragraph and presuppose the presence of another semantic element in the preceding text. For example:

(4) The servant was dog-tired. However, he kept on working.

As said earlier, both local and global conjunctions convey three semantic relationships. Elaboration refers to a relationship of restatement of a previous clause, clause complex or paragraph. Therefore, elaborating conjunctions show that what is to follow is a restatement, exemplification or clarification of what has gone before. Examples 5, 6 and 7 below are instances of paratactic, hypotactic and global elaboration respectively. Note that the conjunction is explicit only in Example 7.

(5) Harry left his room in a mess; he scattered all stuffs across the room.

(6) He measured the shadow of the tower, which was equal to its height.

(7) We are on nodding terms. That is to say, we are not close friends.

Extension is a relationship of either addition or variation. Thus, extending conjunctions indicate that what is to follow is an addition or variation in the message contained in the preceding text. Examples 8, 9 and 10 are explicit instances of the extending paratactic, hypotactic and global conjunctions respectively.

(8) Jim teaches at a school and runs a restaurant.

(9) Whereas the director disagreed with the new proposal, all the technicians said yes.

(10)The defendant said he did not know the plaintiff at all. Furthermore, he denies committing an offence.

Enhancement refers to ways by which one clause, sentence or paragraph can extend on the meanings of another. As such, enhancing conjunctions denote that what is to follow provides some information about the Time, Place, Cause, Condition, Matter, or Manner with regard to the preceding text.

(11)He did not turn up for the appointment, for he had forgotten it.

(12)He is coughing as if he was affected with flu.

(13)The American present-elect Barak Obama has promised a revolutionary change for his nation. For this reason, it seems that this relatively young figure will have a very challenging tenure ahead.

In the examples above, for, as if and for this reason are enhancing paratactic, hypotatic and global conjunctions respectively.

In another classification of conjunctions, Halliday and Hasan (1976) argue that when we use conjunctions as a means of creating text, we may exploit either the relations that are inherent in the phenomena or in the communication. To establish the relations between the goings-on, activities, states, thoughts, etc. in the real world, we make advantage of external conjunctions, whereas to link the relations between two or more ideas in the organizing of the discourse, we benefit from internal conjunctions. Martin (1992) believes that the external conjunctions are concerned with sequences of activities and are hypotactic, but the internal conjunctions are concerned with logically organizing discourse and are global. Admittedly, some conjunctions come out in both local and global contexts in reference to the relations between either the happenings in the world or the organization of the ideas in the text. Table 1 in the Appendix A, offers quite a big picture of the local and global conjunctions classified in terms of logico-semantic functions.

Conjunctions, in general sense, have been widely explored in reading, writing and discourse studies under such labels as conjuncts, connectives, conjunctives, logical connectors, discourse markers, textual metadiscourse, and so forth (Fraser, 1999; Halliday \& Hasan, 1976; Martin, 1992; Quirk et al., 1985; Nippold et al., 1992; Vande Kopple, 1997). As regards reading comprehension, studies have shown that the knowledge of conjunctions is closely related to reading comprehension (Cain, 2003; Geva, 1992; Robertson, 1968). In an attempt to investigate this relationship, Stoodt (1970) came up with this conclusion that there was a significant relationship between the native fourth graders' ability to identify the relationships signaled by conjunctions and reading comprehension. She also found a significant difference in the difficulty of various conjunctions; a significant relationship between comprehension of conjunctions and gender; and a significant difference in comprehension of conjunctions at various socioeconomic levels. To see at what level of proficiency L2 learners handle conjunctions, Geva (1986) and Wu (1994) both realized that the high proficiency ESL learners understood conjunctions at the discourse level better than the intermediate students do; and that low proficiency L2 students could handle logical relationships at the sentence level but not at the extended discourse level. This Implies that the ability to comprehend the logical relations at the clause and sentence levels is necessary but not sufficient, and that the ability to discern logical relations at the discourse level increases with proficiency. Chung (2000) compared four versions of an academic text: a non-signaled text; a text signaled with logical connectives; a text with headings; and a text with signals and headings combined, among poor and good students. The results showed that poor readers relied on explicit logical connectives more than good readers did; and that poor readers made use of logical connectives 
as a guidance to relate sentences with the preceding or subsequence sentences. Moreover, in an investigation to compare native students and non-native ESL students on knowledge on connectors and reading comprehension, Goldman and Murray (1992) discovered that native speakers performed significantly better than the non-native learners did, concluding that understanding of meaning relationships between sentences could lead to betterment in ESL proficiency.

Besides the relationship between conjunctions and reading comprehension, research studies have also been carried out as to the effect of conjunctions on reading comprehension (Chung, 2000; Degand, et al., 1999; Loman \& Mayer, 1983); however, the results have been contradictory. Some hold that conjunctions facilitate the students' reading comprehension. The results of a study by Geva and Ryan (1985), for example, indicated that fifth and seventh graders benefited from the instruction of conjunctions in their performance on reading comprehension of expository texts. Degand and Sanders (2002) investigated the impact of conjunctions on expository text comprehension in L1 and L2. The results showed that the texts bearing explicit causal connectives led to better performance on reading comprehension than the text with implicit causal connectives in both L1 and L2 contexts, concluding that explicit conjunctions had a positive effect on comprehension. On the other hand, some maintain that the conjunctions do not facilitate the students' reading comprehension and may inhibit it. Crewe et al. (1985), for instance, conducted an experimental study that involved two groups of students each receiving a different version of the same academic text: one with the original conjunctions; and the other with the conjunctions eliminated. The findings of this research indicated that there was no significant difference in the performance of the two groups on the reading comprehension assessed by the same comprehension questions devised in accordance with the text content. In the same fashion, Millis et al, (1993) argue that connectives, used to mark coherence relations linguistically, have a negative effect on the mental text representation and do not improve the comprehension of expository texts.

The existing evidence (Chung, 2000; Degand et al., 1999; Geva, 1986; Geva \& Ryan, 1985; Mohammad Salehi, 2005; Stoodt, 1972; Yaghchi, 2000) indicates the conjunctions facilitate reading comprehension of EFL and ESL in some way. However, these studies have either investigated the effect of the explicit instruction of the conjunctions, in general sense, on reading comprehension or looked into the impact of conjunctions on skilled and unskilled students, and have not separately studied the role of the local and global conjunctions in reading comprehension. It is felt necessary to see if a conjunctionally-textured original passage is comprehended as well as the local-conjunctions-free and the globalconjunctions-free versions of the same passage, and if conjunctions affect reading comprehension at the local and/or global level. Thus, this paper attempts to shed more light on the previous findings about the facilitative role of conjunctions, in general, on the reading comprehension of ESL learners, on one hand, and to find out which type of conjunctions, local or global, has more facilitative role on the reading comprehension of the ESL students, on the other hand. To this end, it tries to answer the following research questions.

1) Do conjunctions, in general sense, influence the performance of ESL learners on reading comprehension?

2) To what extent do local conjunctions influence the performance of ESL learners on reading comprehension?

3) To what extent do global conjunctions influence the performance of ESL learners on reading comprehension?

4) Do local conjunctions influence the performance of ESL learners on reading comprehension as much as global conjunctions do?

Based on these research questions, the following null and alternative two-tailed hypotheses are put forward:

$\mathrm{H}_{0}$ : There is no significant difference in the mean reading comprehension scores for those ESL learners who read a conjunctionally-textured passage and those ESL learners who read the conjunctions-free version of the same passage.

$\mathrm{H}_{1}$ : There is a significant difference in the mean reading comprehension scores for those ESL learners who read a conjunctionally-textured passage and those ESL learners who read the conjunctions-free version of the same passage.

\section{METHOD}

This study compared the mean scores on reading comprehension between and within three independent groups of upper-intermediate ESL learners at Universiti Sains Malaysia (USM). The upper-intermediate level was chosen because advanced ESL students, as Geva (1986) holds, are more capable of using the available logical relationships. Each group was given a different version of the same reading comprehension test such that one group received the original modification-free passage; one took a local-conjunctions-free passage; and another received a global-conjunctions-free passage.

\section{A. Subjects}

45 Chinese English learners (36 females and 9 males) who had passed the final test of homogeneity designed for the intermediate level by the Center for Languages and Translation and qualified for the upper-intermediate Intensive English Program in the autumn 2008 in the partial fulfillment of the requirements for admission to Universiti Sains Malaysia at the master's degree were chosen as a sample to this research study. To assign the subjects to different groups, the researchers marked every fifteen pieces of paper with one of the numbers 1, 2 and 3 and put them in a box, then asked each subject to pick up a folded piece of paper from among 45 pieces as an indicator of his/her group. All those who came up with number 1 were assigned to a control group, those with number 2 were assigned to treated group 1 (TG1) and those with number 3 were assigned to treated group 2 (TG2).

\section{B. Materials}


A reading passage in 404 essential tests for IELTS Academic Module was manipulated such that three different forms of the same passage could be constructed: the original reading passage without any modification in the conjunctions, whether local or global; a version of the same reading passage where all 19 local conjunctions - 9 extending and 10 enhancing hypotaxis - had been removed; and another form of the same original passage from which all 10 global conjunctions - 2 elaborating, 4 extending and 6 enhancing - had been eliminated. All three types of the reading passage were followed up with a set of identical questions. These questions were of three different types. The first sort of the questions was related to a table of information with three slots to be completed; the second type of the questions pertained to the matching of a list of nine headings with six paragraphs; and the third kind of the questions was concerned with five fill-in-the-gap questions to be completed with the information from the text. Altogether, there were thirteen question items, which appeared at the end of all the reading passages.

To test the reading comprehension of the subjects in the CG, TG1 and TG2, three different testing techniques for assessing reading comprehension; that is, table completion, multiple matching, and gapped-information completion, were used. The internal consistency computed through Guttman Split-Half coefficient proved that the reliability of this test was acceptable $(\mathrm{r}=0.73)$. To scores the reading comprehension tests, a very simple method was utilized. Accordingly, each question item, of any form, was awarded one point. Therefore, a subject who had 13 correct answers to 13 question items was credited 100 points, and a subject who had no correct answer to 13 question items was awarded with 0 point.

\section{Procedure}

After the reading passage had been made into three different forms, the original passage with both local and global conjunctions was administered to the CG, the local-conjunctions-free passage was given to the TG1, and the globalconjunctions-free passage was administered to the TG2. The researchers discussed the purpose of the study and how to administer the test with three staffs in the Center for Languages and Translation and asked each of them to supervise one of the three groups during the testing and to address the students' problems and questions, if any. All the three groups were spontaneously handed in the question papers by their respective supervisors and told to read through the passage at issue and write the correct answers to the required comprehension questions on the provided answer sheet in not more than 60 minutes.

\section{Analyses}

The variables were entered in the SPSS Program; reading comprehension was defined as an interval-scale dependent variable, and conjunction as a nominal-scale independent variable with three different levels coded as 1, 2 and 3 for the CG, TG1 and TG2 respectively. To determine whether the mean scores for more than two groups with one intervalscale dependent variable and one nominal-scale independent variable are too different to attribute to chance, Analysis of Variance (ANOVA) is an appropriate and effective way (Pallant, 2005). In an effort to check the appropriateness of this parametric statistical technique for this study, it was realized that the assumptions for this statistical test were found to be satisfied: interval-scale dependent variable; normal distribution of the scores (Fig. 1 in Appendix B); and assumed equal variances (Levene's Test value >.05) for the groups (Table 3 in Appendix A). Because there was only one independent variable in the present study, a one-way ANOVA was conducted to reject or accept the null hypothesis of no difference between the groups at the significance level $\alpha<.05$. To check for significance, an F ratio was computed. The value obtained for $\mathrm{F}$ Ratio indicated that the performance of the three groups on reading comprehension was significantly different. Thus, the null hypothesis was rejected at $p<.01$. Moreover, to determine where this significant difference amongst the three groups originated from, a post-hoc test (Scheffe) was conducted.

\section{RESULTS}

The descriptive statistics (Table 2 in Appendix A) showed that there was a consistent difference in the mean scores for all the groups; $\mathrm{CG}_{\mathrm{M}=71.27}>\mathrm{TG} 1_{\mathrm{M}=54.86}>\mathrm{TG} 2_{\mathrm{M}=25.41}$. A one-way ANOVA (Table 4 in Appendix A) run to explore the impact of conjunctions on reading comprehension indicated a statistically significant difference at the $p<.01$ level in the reading comprehension Additionally, the calculation of Eta Squared (sum of squares between groups divided by total sum of squares) indicated that the effect size was .61, which is very large in accordance with the guidelines by Cohen (1988 cited in Pallant, 2005). This meant that 61 percent of the variation in the reading comprehension scores of the groups was due to conjunctions, which explained the meaningfulness of the findings of this study. Post-hoc multiple comparisons (Table 5 in Appendix A) using the Scheffe test showed that all three groups significantly differed from one another at the significance level $p<.05$. The $\mathrm{CG}(\mathrm{M}=71.27, \mathrm{SD}=14.08)$ was significantly different from both the TG1 $(\mathrm{M}=54.86, \mathrm{SD}=20.32)$ and TG2 $(\mathrm{M}=25.11, \mathrm{SD}=11.44)$, and the TG1 was significantly different from the TG2. The means plot (Fig. 2 in Appendix B), too, shows the CG with the highest score and the TG2 with the lowest score.

\section{DISCUSSION}

The results of the statistical analysis above revealed that the mean scores for all three groups in the reading comprehension were significantly different from one another. However, to investigate the effect of the local and global 
conjunctions on reading comprehension of ESL learners as the purpose of this study, the research questions raised at the end of the review of literature are individually addressed here.

1) Do conjunctions, in general sense, influence the performance of ESL learners on reading comprehension?

The means plot (Fig. 2 in Appendix B) clearly displays the different performance of the CG, TG1 and TG2 on reading comprehension. The $\mathrm{CG}$ obtained a mean score greater than both the TG1and the TG2. As the descriptive statistics (Table 2 in Appendix A) illustrates, the CG outperformed the two treated groups in terms of mean score $\left(\mathrm{CG}_{\mathrm{M}=71.27}>\mathrm{TG} 1_{\mathrm{M}=54.86}>\mathrm{TG} 2_{\mathrm{M}=25.11}\right)$. Furthermore, the between-groups analysis of variance (Table 4 in Appendix A) indicates that the difference in the performance of the CG, TG1 and TG2 on reading comprehension is significant $[\mathrm{F}(2,42)=33.19, p<.001]$. That is to say, the ESL learners comprehended the reading text with the ideas explicitly linked to one another through local and global conjunctions better than the reading text with the ideas linked to one another implicitly without the aid of the conjunctions, local or global. This supports the findings of the previous research studies (Chung, 2000; Degand \& Sanders, 2002; Geva, 1992; Geva \& Ryan, 1985; Loman \& Mayer, 1983) that the mere existence of the different types of conjunctions used to signal logico-semantic relations at the local and global levels enables ESL learners to comprehend the reading text more easily. The results of a study by Innajih (2006), who studied the impact of conjunctions on the reading comprehension on 100 Lybian EFL learners, revealed that the group treated with the knowledge of conjunctions outperformed the non-treated group, suggesting that the explicitness of the conjunctions improves reading comprehension.

2) To what extent do local conjunctions influence the performance of ESL learners on reading comprehension?

As Table 2 shows, the TG1 $(\mathrm{M}=54.86, \mathrm{SD}=20.32)$ has a poorer performance on reading comprehension than the $\mathrm{CG}$ $(\mathrm{M}=71.27, \mathrm{SD}=14.08)$ does. Moreover, the post-hoc multiple comparisons (see Table 5) conducted through Scheffe Test to locate the source of the difference indicates that this mean difference in the performance of the CG and TG1 on reading comprehension is a significant at $p<.05$. Consequently, it can be claimed with 95 percent confidence that ESL learners do not comprehend the reading texts that are not linked through local conjunctions as well as the reading texts that are linked by means of conjunctions, in general sense, and that the conjunctions used to link the clause complexes throughout the text play a crucial role in the reading comprehension of ESL learners. As far as the distinction between the local and global conjunctions is concerned, it seems that no research has been reported with respect to the impact of the local conjunctions only on reading comprehension.

3) To what extent do global conjunctions influence the performance of ESL readers on reading comprehension?

From another angle, the post-hoc multiple comparisons indicate that the source of the significant difference between the variables of the current study is not limited to the CG and the TG1, but is also located between the CG and the TG2. As it is seen in Table 5, the mean scores for the CG $(M=71.27, S D=14.08)$ and $C G 2(M=25.11, S D=11.44)$ is different, and further this difference is significant at the $p<.01$ level. This means that the ESL students have poor performance on comprehending the reading text where the ideas at the discourse level are not signaled by the global conjunctions, but good performance on the reading text where the ideas are linked through conjunctions, in general.

The findings here go in agreement with the results of the previous research (Jalilifar \& Alipour, 2007; Geva, 1986; Johnston \& Pearson, 1982; Vahidi, 2008; Wu, 1996), claiming that EFL and ESL learners need to be able to form the correct global coherence of the written text by understanding the global conjunctions that texture the messages and paragraphs together at the discourse level. Cohen and Fine (1978), for example, examined the role of conjunctions in discourse comprehension of native and non-native speakers. They realized that the non-native learners did not effectively exploit cohesive textual relations and failed to comprehend adequately expository texts as a result.

4) Do local conjunctions influence the performance of ESL learners on reading comprehension as much as global conjunctions do?

The descriptive analysis indicates that there is a difference in the mean scores for the TG1 $(M=54.86, S D=20.32)$ and TG2 ( $\mathrm{M}=25.11, \mathrm{SD}=11.44)$. What is more, the results of the Scheffe Multiple Comparisons Test show that this mean difference for the two groups is significant at the $p<.01$ level. To put in another way, the ESL students comprehend the local-conjunctions-free reading text better than the global-conjunctions-free reading text. Thus, it can be claimed that the conjunctions, which signal the global coherence of the ideas at the discourse level, facilitate reading comprehension more than the local conjunctions, which signal the local coherence of the ideas in adjacent sentences. In an investigation to find out whether or not the knowledge of conjunctions plays a role in the reading comprehension of academic texts, Vahidi (1996) examined subjects by three conjunction tasks at three different levels; intra-sentential, inter-sentential and discourse, together with a task of reading comprehension. The results showed that knowledge of conjunctions at discourse level is highly effective in academic reading comprehension. Similarly, the results of studies by Geva (1986) and Chung 2000 suggest that the manipulation of the conjunctions at the discourse level has a differential effect on L2 learners with different levels of proficiency. Accordingly, low proficiency students are less likely to infer implicit logical relationships in the extended contexts, but the advanced L2 learners are more able to deduce such global relationships.

All things considered, the findings of the current research with a significant difference $[\mathrm{F}(2,42)=33.19, p<.001]$ between the three groups $\left(\mathrm{CG}_{\mathrm{M}}>\mathrm{TG} 1_{\mathrm{M}}>\mathrm{TG} 2_{\mathrm{M}}\right)$ rejects the null hypothesis that the ESL learners who read a passage textured by means of conjunctions do not perform better in reading comprehension than the ESL learners who read the same passage with the conjunctions missing and accepts the alternative hypothesis that the ESL learners who read a 
passage textured by means of conjunctions perform better in reading comprehension than the ESL learners who read the same passage with the conjunctions missing.

\section{CONCLUSION}

In an attempt to recognize and tackle the factors that hinder the reading comprehension of ESL learners, the present research aims to investigate, from a systemic perspective, the effect of the local and global conjunctions, used as linguistic resources in the texturing of the written texts, on the reading comprehension of ESL learners. The statistical analysis of the data gathered from one control and two treated groups revealed that conjunctions, in general sense, had a decisive role in the reading comprehension of ESL learners. The local conjunctions used at the local level of the written texts to link clauses together within the scope of the clause complex significantly enhance the understanding of ESL learners. This is advocated by Lotfipour (2006), who affirms that such connectors signaling the type of meaning relationship between two parts of a sentence would facilitate the comprehension process and shorten the computation time. Likewise, the global conjunctions employed to create texture and coherence among the messages, paragraphs and sequences of activities at the global level of the written text effectively influence the reading comprehension of ESL learners. The findings (Jalilifar and Alipour, 2007) show that the removal of the textual connectives from the reading passage affects the reading comprehension ability due to incohesion in the text. Last but not least, the global conjunctions, which concern the internal texturing and organizing of the text information, influence the reading comprehension of ESL learners more than the local conjunctions, which deal with the sequencing of the external events within the sentence. This implies that readers' need to understand conjunctions at the text level is prior to the conjunctions used to link the clauses since readers with sufficient knowledge of discourse patterns use clues for coherence and focus on markers bringing logical relationships to the comprehension of the text (Vahidi, 2006).

Notwithstanding, this research had two noticeable limitations; failure to investigate the role of the three logicosemantic relationships on the reading comprehension, and secondly failure to compare the performance of males and females in the CG and the TGs, which can be of the focal attention in future research.

\section{APPENDIX A}

TABLE 1:

LOCAL AND GLOBAL CONJUNCTIONS IN ENGLISH

\begin{tabular}{|c|c|c|c|c|}
\hline Type of & \multirow{2}{*}{$\begin{array}{c}\text { Global } \\
\text { Between Clause } \\
\text { Complexes }\end{array}$} & \multicolumn{3}{|c|}{ Local } \\
\hline conju & & \multicolumn{2}{|c|}{ Between Clauses } & Within Clause \\
\hline & \multicolumn{4}{|c|}{ Means of Realization } \\
\hline & \multicolumn{3}{|c|}{ Unmarked } & Marked \\
\hline semantic & $\begin{array}{c}\text { Global } \\
\text { Conjunctions }\end{array}$ & $\begin{array}{c}\text { Paratactic } \\
\text { Conjunctions }\end{array}$ & $\begin{array}{c}\text { Hypotactic } \\
\text { Conjunctions }\end{array}$ & Prepositions \\
\hline \multirow{3}{*}{ Elaboration } & in other words, & that is, & which, who & as \\
\hline & for example, & for example & & like \\
\hline & $\begin{array}{l}\text { to be precise, } \\
\text { by the way, } \\
\text { in short, } \\
\text { in particular, etc }\end{array}$ & at least & & \\
\hline \multirow{6}{*}{ Extension } & also & and & while & with \\
\hline & neither & nor & & \\
\hline & however & but & whereas & without \\
\hline & on the contrary & & besides & instead of \\
\hline & otherwise & only & except that & except for \\
\hline & alternatively & or & if not...then & \\
\hline \multirow{14}{*}{ Enhancement } & there & there & wherever & at/in \\
\hline & throughout & & while & for \\
\hline & previously & before/until & before/until & before \\
\hline & next & then & after & after \\
\hline & at once & & as soon as & during \\
\hline & thus & & & by/with \\
\hline & likewise & so & as if & like \\
\hline & therefore & so/for & because & because of \\
\hline & consequently & thus & so that & \\
\hline & to that end & & in order that & for \\
\hline & in that case & then & if & in case of \\
\hline & otherwise & otherwise & unless & without \\
\hline & nevertheless & though & although & despite \\
\hline & in this respect & & & about \\
\hline
\end{tabular}


TABLE 2:

DESCRIPTIVE STATISTICS

\begin{tabular}{|c|c|c|c|c|c|c|c|c|}
\hline & \multirow[b]{2}{*}{$\mathrm{N}$} & \multirow[b]{2}{*}{ Mean } & \multirow[b]{2}{*}{$\begin{array}{c}\text { Std. } \\
\text { Deviation }\end{array}$} & \multirow[b]{2}{*}{ Std. Error } & \multicolumn{2}{|c|}{$\begin{array}{l}95 \% \text { Confidence } \\
\text { Interval for Mean }\end{array}$} & \multirow[b]{2}{*}{ Minimum } & \multirow[b]{2}{*}{ Maximum } \\
\hline & & & & & $\begin{array}{l}\text { Lower } \\
\text { Bound }\end{array}$ & $\begin{array}{l}\text { Upper } \\
\text { Bound }\end{array}$ & & \\
\hline CG & 15 & 71.27 & 14.08 & 3.63 & 63.47 & 79.07 & 46.15 & 92.30 \\
\hline TG1 & 15 & 54.86 & 20.32 & 5.24 & 43.61 & 66.12 & 23.07 & 92.30 \\
\hline TG2 & 15 & 25.11 & 11.44 & 2.95 & 18.77 & 31.45 & 7.69 & 46.15 \\
\hline Total & 45 & 50.41 & 24.68 & 3.68 & 43.00 & 57.83 & 7.69 & 92.30 \\
\hline
\end{tabular}

TABLE 3:

TEST OF HOMOGENEITY OF VARIANCES

Reading Comprehension

\begin{tabular}{|c|c|c|c|}
\hline Levene Statistic & $\mathrm{df1}$ & $\mathrm{df2}$ & Sig. \\
\hline 2.696 & 2 & 42 & .079 \\
\hline
\end{tabular}

TABLE 4:

ANOVA

Reading Comprehension

\begin{tabular}{|l|c|c|c|c|c|}
\hline & Sum of Squares & df & Mean Square & F & Sig. \\
\hline Between Groups & 16427.50 & 2 & 8213.75 & 33.19 & .000 \\
Within Groups & 10393.27 & 42 & 247.45 & & \\
Total & 26820.77 & 44 & & & \\
\hline
\end{tabular}

TABLE 5:

Post Hoc Tests: MulTIPLE COMPARISONS

Reading Comprehension

Scheffe

\begin{tabular}{|c|c|c|c|c|c|c|}
\hline \multirow{2}{*}{$\begin{array}{l}\text { (I) } \\
\text { Conjun } \\
\text { ction }\end{array}$} & \multirow{2}{*}{$\begin{array}{l}(\mathrm{J}) \\
\text { Conjun } \\
\text { ction }\end{array}$} & \multirow{2}{*}{$\begin{array}{c}\text { Mean Difference } \\
(\mathrm{I}-\mathrm{J})\end{array}$} & \multirow[b]{2}{*}{ Std. Error } & \multirow[b]{2}{*}{ Sig. } & \multicolumn{2}{|c|}{$95 \%$ Confidence Interval } \\
\hline & & & & & Lower Bound & Upper Bound \\
\hline \multirow[t]{2}{*}{$\mathrm{CG}$} & TG1 & $16.41^{*}$ & 5.74 & .02 & 1.83 & 30.98 \\
\hline & TG2 & $46.16^{* *}$ & 5.74 & .00 & 31.58 & 60.73 \\
\hline \multirow[t]{2}{*}{ TG1 } & CG & $-16.41^{*}$ & 5.74 & .02 & -30.98 & -1.83 \\
\hline & TG2 & $29.75^{* *}$ & 5.74 & .00 & 15.17 & 44.32 \\
\hline \multirow[t]{2}{*}{ TG2 } & CG & $-46.16^{* *}$ & 5.74 & .00 & -60.73 & -31.58 \\
\hline & TG1 & $-29.75^{* *}$ & 5.74 & .00 & -44.32 & -15.17 \\
\hline
\end{tabular}

*. The mean difference is significant at the 0.05 level.

**. The mean difference is significant at the 0.01 level.

TABLE 6:

HOMOGENEOUS SUBSETS

Scheffe

\begin{tabular}{|l|c|c|c|c|}
\hline \multirow{2}{*}{ Conjunction } & \multirow{2}{*}{$\mathrm{N}$} & \multicolumn{3}{|c|}{ Subset for alpha $=0.05$} \\
\cline { 3 - 5 } & $\mathrm{N}$ & 1 & 2 & 3 \\
\hline TG2 & 15 & 25.11 & & \\
TG1 & 15 & & 54.86 & \\
CG & 15 & & & 71.27 \\
Sig. & & 1.00 & 1.00 & 1.00 \\
\hline
\end{tabular}

Means for groups in homogeneous subsets are displayed. 


\section{APPENDIX B}
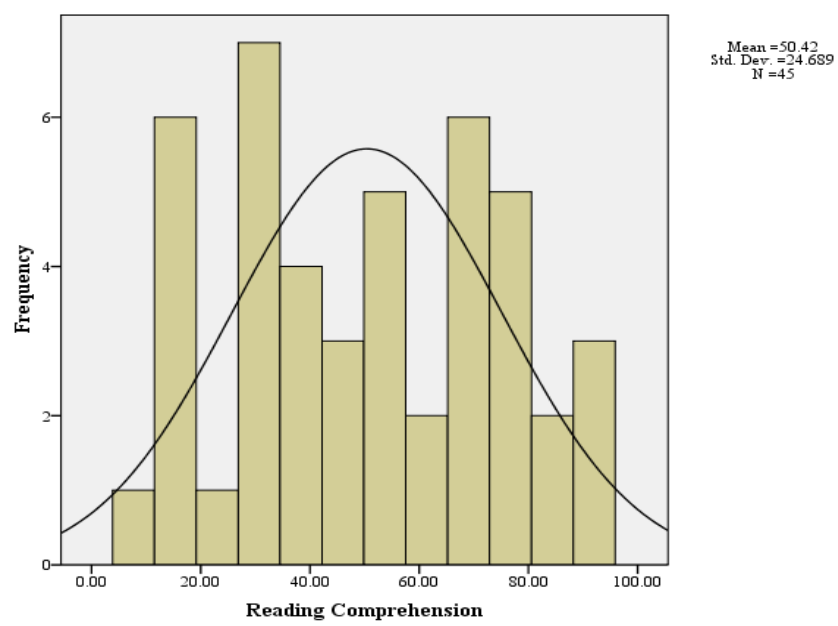

Figure 1: Normal Distribution of Reading Comprehension Scores

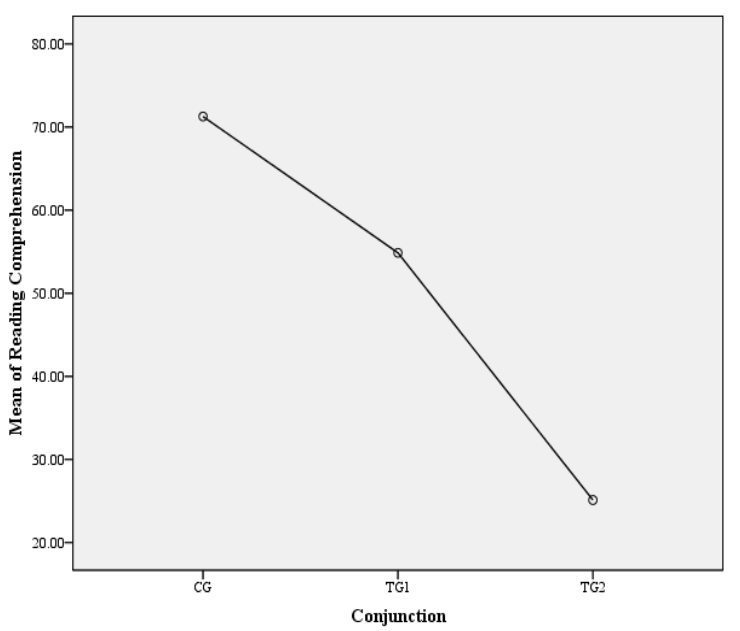

Figure 2: Means Plots

\section{ACKNOWLEDGEMENTS}

We would like to thank the Institute of Postgraduates Studies (IPS) at Universiti Sains Malaysia (USM), Malaysia for the financial support for this research study funded in the form of a fellowship. Our thanks also go to Dr. Shaikh Abdul Malik Mohamed Ismail for his invaluable timely comments.

\section{REFERENCES}

[1] Cain, K. (2003). Text comprehension and its relation to coherence and cohesion in children's functional narratives. British Journal of Developmental Psychology, 21, 335-351.

[2] Carrell, P. L. (1988). Interactive text processing: implication for ESL/second language reading classrooms. In P. Carrel, J. Devine, \& D. Eskey (Eds.). Interactive approaches to second language reading. New York: Cambridge University Press.

[3] Chung, J. S. L. (2000). Signals and reading comprehension - theory and practice. System, 28(2), 247-259.

[4] Cohen, J. (1988). Statistical power analysis for the social behavioral sciences. Hillsdale, NJ: Erlbaum.

[5] Cohen, A. D., \& Fine, J. (1978). Reading history in English: Discourse analyses and the experience of native and non-native readers. Working Papers on Bilingualism, 16.

[6] Crewe, W., Wright, C., \& Leung, M. W. K. (1985). Connectives: On the other hand, who needs them, though? Working papers in Applied Linguistics and Language Teaching, 8, 61-65.

[7] Degand, L., Lefevre, N., \& Bestgen, Y. (1999). The impact of connectives and anaphoric expressions on expository discourse comprehension. Document Design, 1, 39-51.

[8] Degand, L., \& Sanders, T. (2002). The impact of relational markers on expository text comprehension in L1 and L2. Reading and writing: An Interdisciplinary Journal, 15, 739-757.

[9] Eskey, D. E., \& Grabe, W. (1988). Interactive models for second-language reading: perspectives on interaction. In P. Carrell, J. Devine \& D. Eskey (Eds.), Interactive approaches to second language reading. New York: Cambridge University Press. 
[10] Fraser, B. (1999). What are discourse markers? Journal of Pragmatics. 31(7), 931-952.

[11] Geva, E. (1986). Reading comprehension in a second language: the role of conjunctions. TESL Canada Journal, Special Issue 1.

[12] Geva, B. (1992). The role of conjunctions in L2 text comprehension. TESOL Qarterly, 26 (4), 731-747.

[13] Geva, B., \& Ryan, E. B. (1985). Use of conjunctions in expository texts by skilled and less skilled readers. Journal of Reading Behaviour, 17 (4), 331-346.

[14] Goldman, S. R., \& Murray, J. D. (1992). Knowledge of connectors as cohesion devices in text: a comparative study of nativeEnglish and English-as-a-Second Language speakers. Journal of Educational Psychology, 84(4), 504-519.

[15] Grabe, W. (1988). Reassessing the term 'interactive'. In P. Carrell, J. Devine \& D. Eskey (Eds.), Interactive approaches to second language reading (pp.56-70). New York: Cambridge University Press.

[16] Grabe, W., \& Stoller, F. L. (2002). Teaching and researching reading. Longman: Pearson Education.

[17] Halliday, M. A. K., \& Matthiessen, C. M. I. M. (2004). An introduction to functional grammar (3 ${ }^{\text {rd }}$ ed.). London: Edward Arnold.

[18] Halliday, M. A. K., \& Hasan, R. (1976). Cohesion in English. London. Longman.

[19] Innajih, A. (2006). The impact of textual cohesive conjunctions on the reading comprehension of foreign language students. ARECLS e-journal, 3, 1-20.

[20] Jalilifar, A., \& Alipour, M. (2007). How explicit instruction makes a difference: metadiscourse makers and EFL learners' reading comprehension skill. Journal of College Reading and Learning (Fall).

[21] Johnson, P., \& Pearson, D. P. (1982). Prior knowledge, connectivity, and the assessment of reading comprehension (Tech. Rep. No. 245). Urbana: University of Illinois.

[22] Loman, N, L., \& Mayer, R. E. (1983). Signalling techniques that increase the understandability of expository prose. Journal of Education Psychology, 73(3), 402-412.

[23] Lotfipour, S. K. (2006). Towards the textuality of a text: on a grammar for communication. Tabriz: Forouzesh Publications.

[24] Martin, J. R. (1992). English text: system and structure. Amsterdam: Benjamins.

[25] Millis, K. K., Graesser, A. C., \& Haberlandt, K. (1993). The impact of connectives for memory for expository texts. Applied Cognitive psychology 7, 317-339.

[26] Mohammad Salei, B. (2005). The effect of explicit teaching of logical connectives on ESP reading comprehension of Iranian students. Unpublished Master's Thesis. Teacher Training University.

[27] Nippold, M. A., Schwarz, I. E. \& Undlin, R. A. (1992). Use and understanding of adverbial conjuncts: a developmental study of adolescents and young adults. Journal of Speech and Hearing Research, 25, 108-118.

[28] Quirk, R. Greenbaum, S. Leech, G., \& Sartvik, J. (1985). A comprehensive grammar of the English language. London: Longman.

[29] Roberston, J. E. (1968). Pupil understanding of connectives in reading. Reading Research Quarterly, 3, 387-417.

[30] Stoodt, B. D. (1970). The relationship between understanding grammatical conjunctions and reading comprehension (Project No. 2991). Ohio: The Ohio State University

[31] Vahidi, S. (1996). A study on the role of conjunctions in academic/expository text composition. Unpublished Master's Thesis. Shiraz University.

[32] Vahidi, S. (2008). The impact of EFL learners' rhetorical organization awareness on English academic/expository text comprehension. Pazhuhesh-e Zabanha-ye Khareji, 41, 145-158.

[33] Vande Kopple, W. J. (1997). Refining and applying views of metadiscourse. Paper presented at the $48^{\text {th }}$ Annual Meeting of the Conference on College composition and Communication, Phoenix, Az.

[34] Wu, J. S. (1994). A study on college-level Chinese students' use of conjunctions and their reading comprehension. Unpublished Master's Thesis. National Chengchi University.

[35] Yaghchi, M. A. (2000). The impact of formal instruction of references and conjunctions on reading comprehension of Iranian EST students. Unpublished MA Thesis. Iran University of Science and Technology.

Nader Assadi Aidinlou is a lecturer at Islamic Azad University, Ahar Branch in Iran. He has received his BA and MA in Teaching English as a Foreign Language (TEFL) in Iran and is currently a research fellow at Universiti Sains Malaysia. His areas of interest are Applied Linguistics, Systemic Functional Linguistics, Discourse Analysis and Reading. He has authored and co-authored many national and international papers.

Ambigapathy A/L Pandian is a Professor, Dean at the School of Languages, Literacies and Translation and head of International Literacy Research Unit, USM in Penang, Malaysia. He also serves as a research Fellow at the National Higher Education Research Institute, Ministry of Education Malaysia. His field of research interests includes language and literacy education, Teaching English to Speakers of Other Languages, Sociolinguistics and recently on higher education. He is very well published, being the author and editor of more than 20 books and many articles featured in local and International journals. 